\title{
Histologic and sonographic features of holmium laser in the treatment of chronic venous disease
}

\author{
Sergio GIANESINI ${ }^{1}$ *, Roberta GAFÀ ${ }^{2}$, Savino OCCHIONORELLI ${ }^{1}$, Erica MENEGATTI ${ }^{1}$, \\ Anna Maria MALAGONI ${ }^{1}$, Paolo SPATH ${ }^{1}$, Giovanni LANZA ${ }^{2}$, Paolo ZAMBONI ${ }^{1}$
}

\footnotetext{
${ }^{1}$ Vascular Disease Center, Unit of Translational Surgery, Ferrara, Italy; ${ }^{2}$ Department of Pathology, University of Ferrara, Ferrara, Italy

*Corresponding author: Sergio Gianesini, Vascular Disease Center, University of Ferrara, Via Aldo Moro 8, Cona, 44123 Ferrara, Italy.

E-mail: sergiogianesini@gmail.com
}

\section{A B S T R A C T}

BACKGROUND: A new holmium laser (HOL) has been introduced to the market. The device is able to reduce the great saphenous vein (GSV) caliber in a tumescence-free procedure, favoring an effective sclerotherapy of large vessels. Aim of the present investigation is to provide the first in vivo data about the effect of HOL on GSV histology.

METHODS: Six chronic venous disease $\left(\mathrm{C}_{2-5}\right.$, Ep, As, Pr) patients (M:F ratio 1:1; age: $57 \pm 8$, BMI $\left.24 \pm 2 \mathrm{~kg} / \mathrm{m}^{2}\right)$ underwent HOL-assisted caliber reduction of the GSV, high-ligation and flush ligation of the incompetent tributaries. Three $\mathrm{cm}$ of proximal great saphenous vein not treated by laser and $3 \mathrm{~cm}$ of a contiguous segment that was just previously treated by HOL were harvested.

Histological assessments were performed. Patent GSV lumen caliber was assessed at the mid-thigh right before, and after the procedure. Periprocedural pain was graded by Visual Analogue Scale.

RESULTS: GSV samples after holmium laser therapy showed thickening of the vascular wall with a decreased, yet patent lumen. Immunostaining demonstrated intact endothelial lining in both the treated and not treated segments. Expansion of collagen fibers was observed in the laser-treated segments. Collagen appeared more homogeneous than in controls, with an amorphous appearance. Laser treated veins showed a reduction in elastic fibers with greater fragmentation. Smooth muscle cells appeared swollen. The caliber of the mid-thigh great saphenous vein lumen decreased from $8.1 \pm 0.8 \mathrm{~mm}$ to $3.9 \pm 0.2 \mathrm{~mm}(\mathrm{P}<0.0001)$. The average periprocedural pain was $1 \pm 0.6$.

CONCLUSIONS: HOL significantly reduces the caliber of the GSV. The endothelial lining is spared, while the remaining wall is thickened by a hyalinization-like process.

(Cite this article as: Gianesini S, Gafà R, Occhionorelli S, Menegatti E, Malagoni AM, Spath P, et al. Histologic and sonographic features of holmium laser in the treatment of chronic venous disease. Int Angiol 2017;36:122-8. DOI: 10.23736/S0392-9590.16.03652-X)

Key words: Solid-state lasers - Holmium - Ablation techniques - Laser therapy - Sclerotherapy.

$\mathrm{E}^{\mathrm{n}}$ ndovenous thermal ablation has become a mainstay in the treatment of saphenous reflux ${ }^{1}$ and is recommended as the best treatment option by international guidelines. ${ }^{2,3}$ So far, the main thermal sources for endovenous ablation are radiofrequency ablation (RFA) and endovenous laser ablation (EVLA). 4,5 They are currently preferred over surgery, because they are safe and minimally invasive. ${ }^{2,3}$

By introducing a fiber into the saphenous vein, thermal energy is delivered intra-luminally and absorbed by blood and vein wall. The aim of these techniques is to ablate the refluxing vein in a minimally invasive way. Nevertheless, tumescent anesthesia is required, leading to possible patient discomfort, occasional hematomas and to extremely rare but serious complications such as fiber fracture.6,7

Recently, an innovative holmium laser (HOL) has been introduced to the market, offering the consistent advantage of not requiring tumescent anesthesia. This device is able to reduce the great saphenous vein (GSV) caliber, allowing immediate, subsequent foam sclerotherapy, even in the largest veins. The strategy is known 


\section{COPYRIGHT $^{(} 2017$ EDIZIONI MINERVA MEDICA}

by the acronym LAFOS (Laser Assisted FOam Sclerotherapy). ${ }^{8}$ The specific effect of HOL is strictly related to the average lower temperature generated by the device in comparison to traditional RFA and EVLA: $42{ }^{\circ} \mathrm{C}$ versus more than $100{ }^{\circ} \mathrm{C}$, respectively. ${ }^{8-11}$

Endovenous thermal ablation techniques will likely continue to play a persistent major role among modern and future phlebology therapeutic options. Nevertheless, their mechanistic features on the venous histologic layers and the related biological effects are described just by a limited number of papers. ${ }^{12}$

The aim of the present morphologic investigation is to provide a detailed description of the effect of $\mathrm{HOL}$ on the venous wall that can be used as a basis for future, deeper comprehension of the phenomena governing the action, and thus the performance of endovenous devices.

\section{Materials and methods}

Six chronic venous disease patients $(\mathrm{M} / \mathrm{F}: 1 / 1$; Age:57 \pm 8 ; BMI:24 \pm 2$)\left(\mathrm{C}_{2}, 2\right.$ cases; $\mathrm{C}_{3}, 2$ cases; $\mathrm{C}_{4}, 1$ case; $\mathrm{C}_{5}, 1$ case $)\left(\mathrm{C}_{2-5}\right.$, Ep, As, Pr) underwent a single procedure that included a HOL assisted caliber reduction of the GSV from the groin downward, a saphenofemoral surgical high-ligation and a flush ligation of the incompetent saphenous tributaries along the leg. The HOL fiber (800 microns) was inserted directly into the GSV right above the knee by a $17-\mathrm{G}$ needle. Neither a guide-wire nor tumescent anesthesia was used.

After positioning the device $3 \mathrm{~cm}$ below the saphenofemoral junction, HOL was used in short pulse mode $(350 \mu \mathrm{s})$, delivering $300 \mathrm{~mJ}$ per pulse at a frequency of $7 \mathrm{~Hz}$ for a total of $2.1 \mathrm{~J} / \mathrm{s}$. HOL was used in 3 repeated cycles of $2.5 \mathrm{~s}$ each, during which the fiber was kept in the same position, moving distally $1 \mathrm{~cm}$ after delivering $16 \mathrm{~J} / \mathrm{cm}$.

Subsequently, a high ligation was performed at the groin under local anesthesia. During the high ligation, $3 \mathrm{~cm}$ of proximal GSV not treated by HOL and $3 \mathrm{~cm}$ of the contiguous distal segment that was just previously treated by HOL were harvested.

All patients signed an informed consent prior to the procedure. Institutional Review Board approval was obtained.

For the histopathologic study, multiple sections of the samples were stained with standard ematoxylin-eosin, orcein staining (a specific histochemical staining used to identify elastic fibers) and Masson trichrome staining (a histochemical staining used to identify collagen fibers and muscle fibers).

Immunohistochemistry was also employed to verify the presence of factor VIII - which is normally expressed in endothelial cells - and of actin — which is normally expressed in smooth muscle cells.

Patent GSV lumen caliber was assessed at the midthigh right before and after the procedure in the supine position.

Periprocedural HOL-induced pain was graded by Visual Analogue Scale ranging from 0 (no pain) to 10 (unbearable pain). ${ }^{15,16}$

\section{Statistical analysis}

InStat GraphPad (GraphPad Software, Inc., La Jolla, CA, USA) was used for statistical analysis. The data were expressed as mean \pm standard deviation. The normal distribution of the data was verified by the Kolmogorov-Smirnov test. The differences between vein diameters pre- and post-procedure were performed using two-tailed paired Student's $t$-test. A P value of 0.05 or less was considered statistically significant.

\section{Results}

All 6 harvested samples were suitable for histological analysis. Gross examination of the GSV after HOL therapy showed a conspicuous thickening of the vascular wall with a decreased patent lumen (Figure 1).

On microscopic examination, the vascular wall showed sub-intimal fibrosis and hypertrophy of the smooth muscle coat in both HOL treated and not treated samples, because of the common chronic venous disease condition.

The endothelial lining remained intact in both groups, as demonstrated by factor VIII immunostaining (Figure 2). Various constituents of the vascular wall showed structural alterations. Compared to the contiguous GSV tract (Figure 3A) that was not previously shrunken, HOL samples demonstrated an expansion of the collagen fibers, with a more homogeneous hyalinization-like amorphous appearance and a loss of normal fibrillar characteristics (Figure 3B). In HOL treated samples, orcein staining demonstrated a significant reduction in elastic fibers with 


\section{COPYRIGHT $^{(\odot)} 2017$ EDIZIONI MINERVA MEDICA}
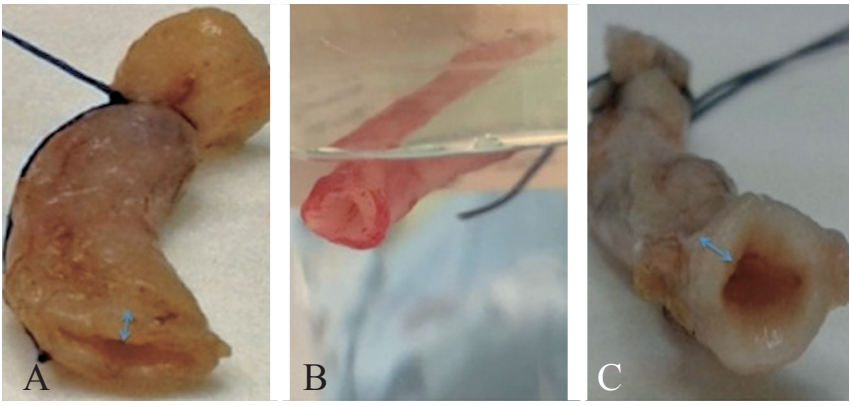

Figure 1.-Macroscopic comparative evaluation among GSV not treated by HL (A) and the GSV immediately below that was previously treated by $\mathrm{HL}(\mathrm{B}, \mathrm{C})$. A clearly thickened wall is detected both at the harvesting (B) and after histological fixation (C).

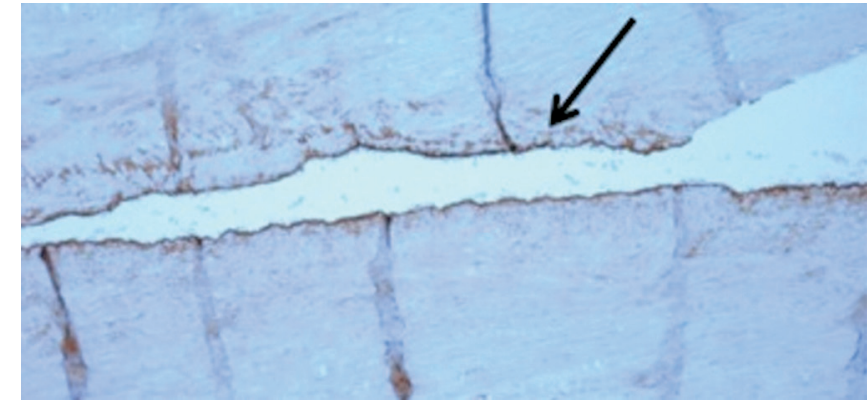

Figure 2.-Brown staining (black arrow) of endothelial cells with factor VIII immunostaining after HL shrinkage of the GSV (4X).

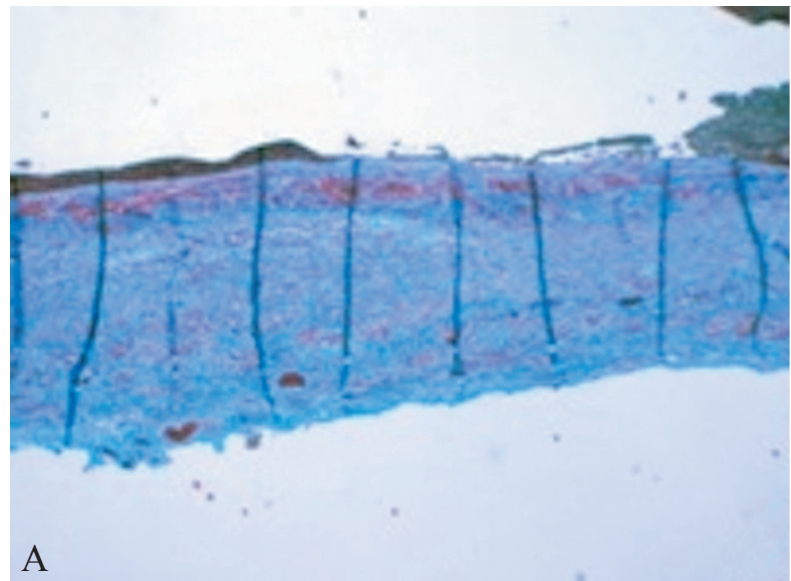

B

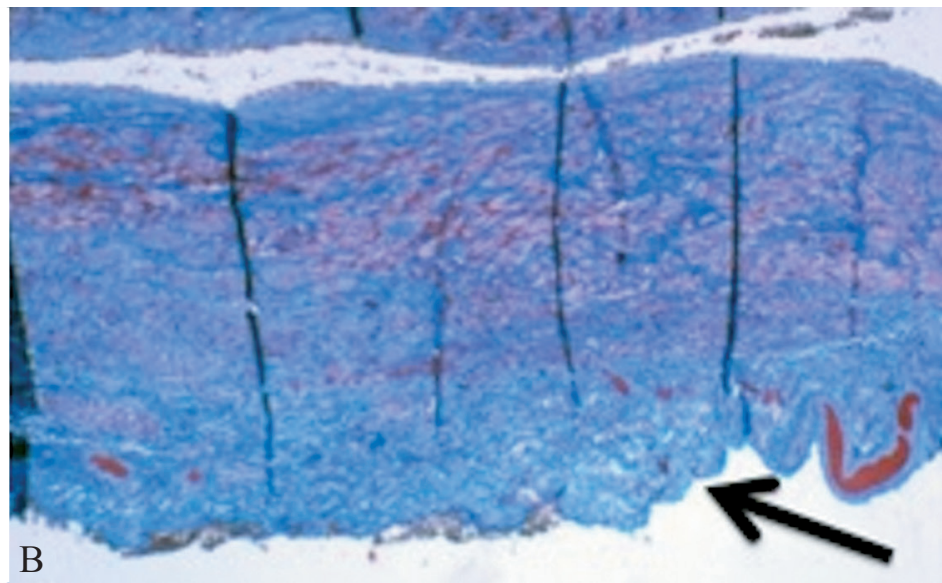

Figure 3.- GSV tract not treated by HL (trichrome staining $2 \times)(3 \mathrm{~A})$ compared to the contiguous GSV segment treated by HL (trichrome staining $2 \mathrm{X})(3 \mathrm{~B})$. An expansion of the collagen fibers is clearly evident, in particular near the adventitia after the HL shrinkage (arrow, blue staining).

great fragmentation. Loss of the normal weave was clearly appreciated just in the HOL treated samples and not in the contiguous venous segment (Figure 4).

Actin immunostaining demonstrated significant swelling in the HOL samples that was not detected in the contiguous GSV segments (Figure 5).

After HOL shrinkage, thickening of the media was immediately detected by intraoperative sonographic scanning, together with a hyperechoic line at the border of the media and adventitia (Figure 6A). Even if shrunken, the venous lumen remained patent and, before the high-ligation, inhabited by a thoracic pump activated flow (Figure 6B). Caliber of the patent mid-thigh GSV lumen decreased from $8.1 \pm 0.8 \mathrm{~mm}$ to $3.9 \pm 0.2 \mathrm{~mm}$ $(\mathrm{P}<0.0001)$ (Figure 6). The average periprocedural pain was $1 \pm 0.6$.

Neither minor nor major complications were reported.

\section{Discussion}

$\mathrm{HOL}$ is a device that has been on the market for more than a decade. Its main application has been in urology and orthopedics. Nowadays however, it is used in several other specialties including general surgery, neurosurgery, dentistry and phlebology. $8,13,14$

It is a pulsed Ho:YAG laser that uses a wavelength of $2100 \mathrm{~nm}$, thus highly absorbed by water. ${ }^{15}$

In the phlebology setting, a HOL pulse lasts $350 \mu \mathrm{s}$ and delivers from 100 to $500 \mathrm{~mJ}$ in cycles of $7 \mathrm{~Hz}$, creating a peak temperature of $76^{\circ} \mathrm{C}$ that is responsible for the shrinkage.

The average temperature never rises above $42{ }^{\circ} \mathrm{C}$.

Until now, a limited number of histopathological evaluations have been performed on venous walls following EVLA and RFA treatments. ${ }^{16-19}$ 

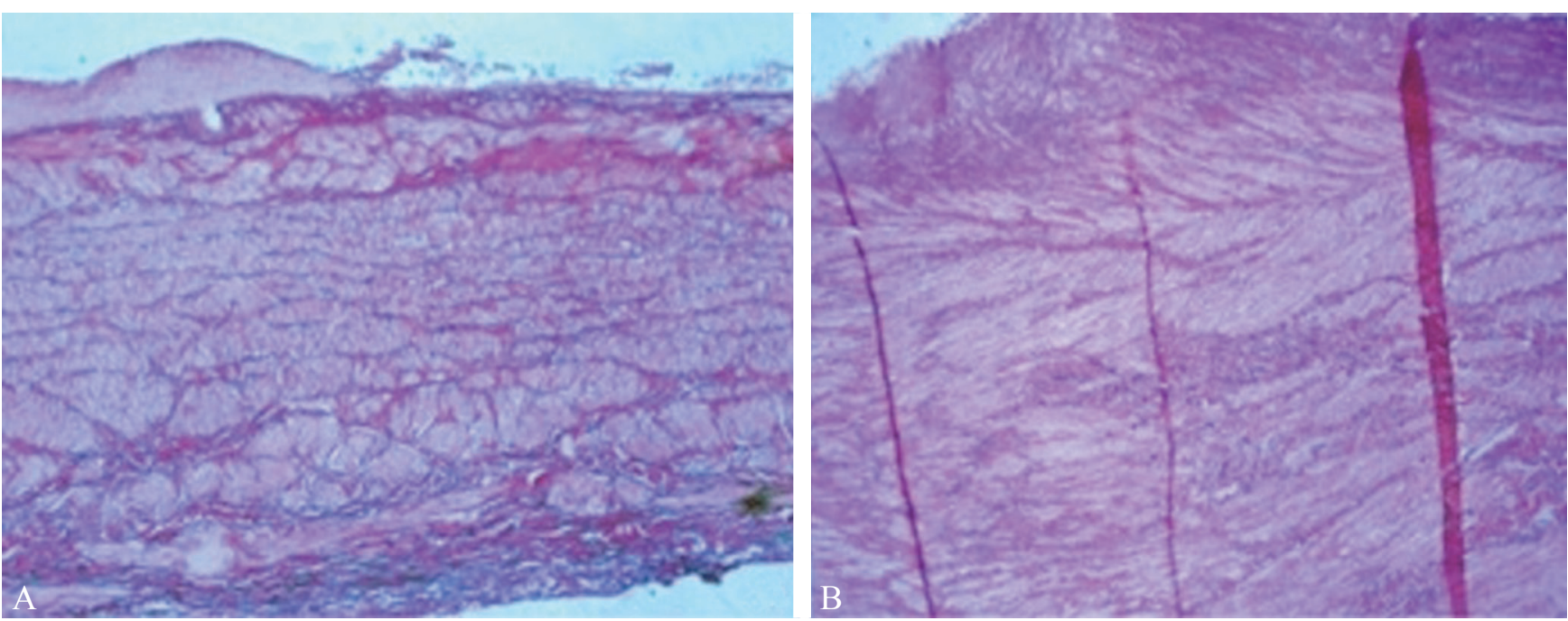

Figure 4.-A) Normal representation of elastic fibers (orcein staining $4 \times$ ) in the segment not treated by HL. B) Significant reduction in elastic fibers with fragmentation and loss of normal weave after HL use in contiguous GSV segment in the same patient (orcein staining 4×). A) GSV segment not treated by HL compared to the contiguous GSV tract that was previously treated by HL. B) Significant swelling of smooth muscle cells is demonstrated after HL use by actin immunostaining $(4 \times)$.
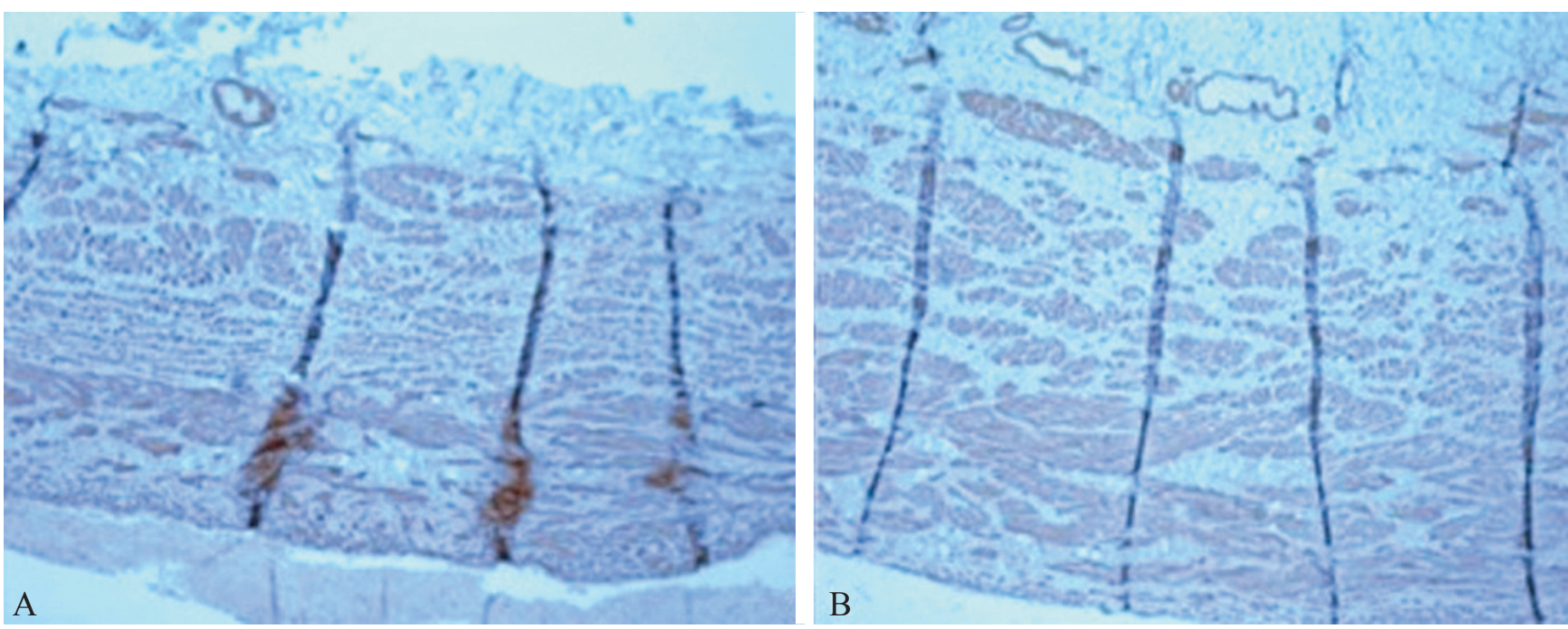

Figure 5.-A) GSV segment not treated by HL compared to the contiguous GSV tract that was previously treated by HL. B) Significant swelling of smooth muscle cells is demonstrated after HL use by Actin immunostaining (4X).

The high temperature produced by EVLA and RFA is associated with macroscopic induration of the vessel. Microscopic assessments have demonstrated endothelial and media disintegration, smooth muscle cell swelling and transmural thermal lesions. ${ }^{16,17,20,21}$

Previous investigations have also reported a risk of venous perforation that was higher in continuous rather than pulsed lasers: a phenomenon that was linked to the carbonization and significant heating of the fiber tip. ${ }^{20,22}$

In contrast to RFA and EVLA, the current investigation demonstrates that the lower temperature of $\mathrm{HOL}$ spares the endothelium. ${ }^{20,21}$ 


\section{COPYRIGHT $^{(} 2017$ EDIZIONI MINERVA MEDICA}

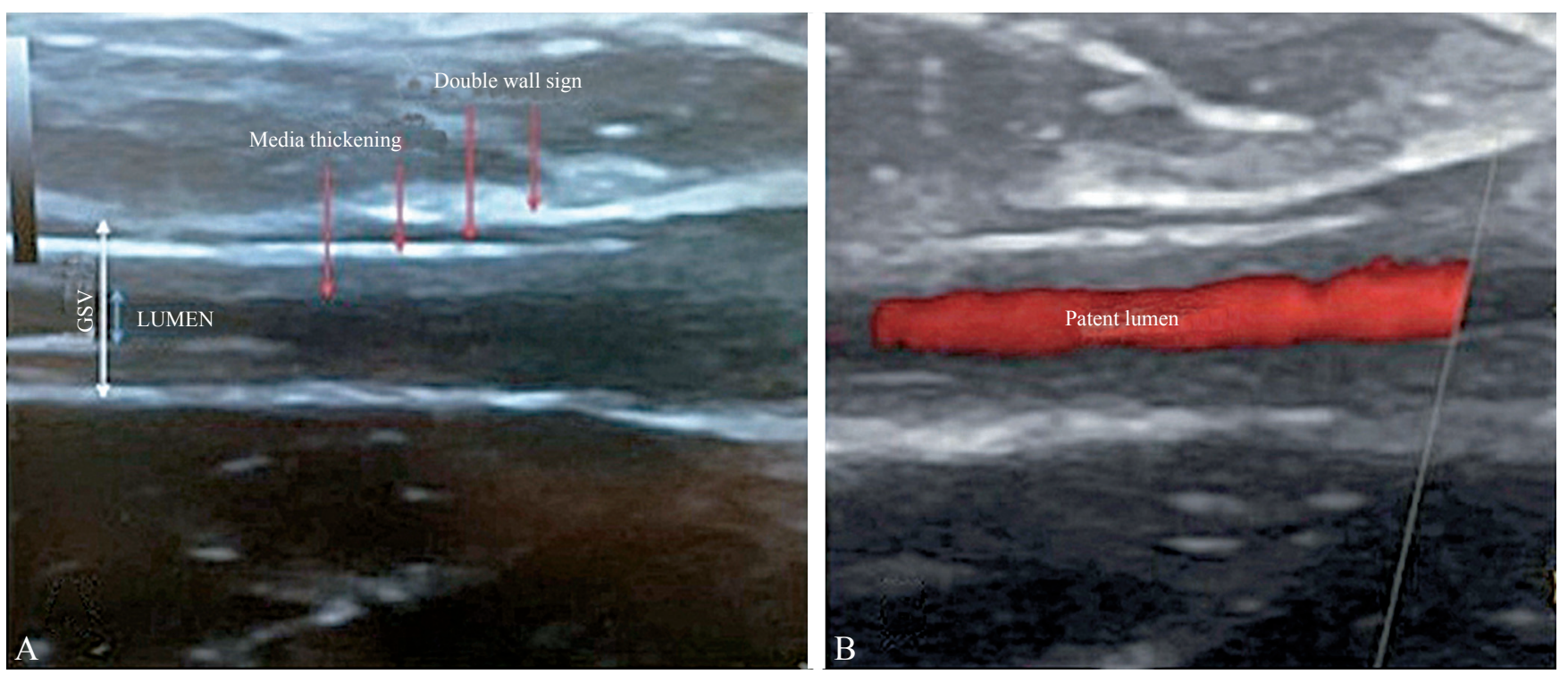

Figure 6.-A Venous wall thickening after HL shrinkage. A "double wall sign" is created by the appearance of the adventitia and the hyperechogenic line that is produced after HL use. A narrower but still patent lumen is clearly evident by color-Doppler investigation (B).

Collagen denatures between $50^{\circ} \mathrm{C}$ and $60{ }^{\circ} \mathrm{C} .23$

The circulating blood represents a fundamental factor in the process of wall cooling.

In fact, during the pulsed HL switched off phase, the endothelium is cooled by the thermal convection that is created by venous flow. Conversely, the media layer can only cool by conduction, a slower phenomenon that requires more time than the same HL switched off phase.

For this reason, the media layer progressively reaches temperatures above $60{ }^{\circ} \mathrm{C}$, leading to wall damage despite the endothelium sparing. $8,20,24$

The present investigation demonstrates how, despite mild thermal damage, the microscopic features of the media are similar to those detected after effective high temperature RFA and EVLA: collagen denaturation, elastic fiber fragmentation, and smooth muscle cell swelling. At the same time, neither splits and gaps, nor wall perforations were reported in HOL samples.

Like traditional endovenous thermal devices, HOLinduced wall damage leads to a chronic rather than transitory process.

In the present investigation, a consequent lumen reduction was detected by intraoperative Doppler scanning. The efficacy of foam sclerotherapy is limited by GSV caliber. ${ }^{25,26}$
The HOL-induced vessel caliber reduction paves the way for more effective sclerotherapy, decreasing the risks linked to high sclerotherapy drug concentrations. ${ }^{27,} 28$

Further investigations should assess the histopathological evolution of this brand new type of shrinkage over time, together with the eventual biological consequences of an intact endothelium. The HOL-induced low temperature also brings the great advantage of a tumescent free and painless office-based procedure. Another benefit comes from patient feedback in the absence of any anesthesia, so providing a potential further reduction of the neurological and thermal complications that are already diminished by the significantly lower energy delivered by HOL. ${ }^{29}$

The saphenous-sparing strategies' satisfying recurrence rate 30,31 together with the mini-invasiveness of the modern endovenous techniques 32 have progressively stimulated pioneering investigations regarding GSV competence restoration by means of endovenous devices. ${ }^{33-35}$

In this environment, HOL offers the chance to switch from an ablative tool, as in LAFOS strategy, to a potential means of GSV flow restoration without the need of any subsequent foam sclerotherapy. Further hemodynamics investigations on this topic are currently on- 
going and known as LAFE (Laser-Assisted Flow Enhancement).

Despite significant investigations in endovenous thermal techniques, there is still a lack of agreement regarding their principles of action and consequent therapeutic strategies. ${ }^{36}$

HOL adds a new histopathological scenario to the thermal induced venous wall evaluations, thus providing not only a potentially effective tumescent free therapeutic option, but also a deeper understanding of pathophysiology.

\section{Conclusions}

HOL offers a new option for tumescence-free treatment of varicose veins. The device reduces saphenous caliber, however investigations on the topic are lacking. This investigation provides the first in vivo evidences of the effect of HOL on the endothelium and on the remaining vessel wall, as well as the immediate reduction of vein caliber. The data offer the basis for further study on the histologic effects durability together with investigations addressed to increasing the efficacy of present and future endovenous thermal devices.

\section{References}

1. Niedzwiecki G. Endovenous Thermal Ablation of the Saphenous Vein. Semin Intervent Radiol 2005;22:204-8.

2. Gloviczki P, Comerota AJ, Dalsing MC, Eklof BG, Gillespie DL, Gloviczki ML, et al. The care of patients with varicose veins and associated chronic venous diseases: clinical practice guidelines of the Society for Vascular Surgery and the American Venous Forum. J Vasc Surg 2011;53:2S-48S.

3. Wittens C, Davies AH, Bækgaard N, Broholm R, Cavezzi A, Chastanet $\mathrm{S}$, et al. Editor's Choice - Management of Chronic Venous Disease: Clinical Practice Guidelines of the European Society for Vascular Surgery (ESVS). Eur J Vasc Endovasc Surg 2015;49:678737.

4. Min RJ, Zimmet SE, Isaacs MN, Forrestal MD. Endovenous laser treatment of the incompetent greater saphenous vein. J Vasc Interv Radiol 2001;12:1167-71.

5. Holdstock JM, Marsh P, Whiteley MS, Price BA. It is possible to cause damage to a laser fibre during delivery of tumescent anaesthesia for endovenous laser ablation (EVLA). Eur J Vasc Endovasc Surg 2008;36:473-6.

6. Holdstock JM, Marsh P, Whiteley MS, Price BA. It is possible to cause damage to a laser fibre during delivery of tumescent anaesthesia for endovenous laser ablation (EVLA). Eur J Vasc Endovasc Surg 2008;36:473-6.

7. Lun Y, Shen S, Wu X, Jiang H, Xin S, Zhang J. Laser fiber migration into the pelvic cavity: A rare complication of endovenous laser ablation. Phlebology 2015;30:641-3.

8. Frullini A, Fortuna D. Laser assisted foam sclerotherapy (LAFOS): a new approach to the treatment of incompetent saphenous veins. Phlebologie 2013;66:51-4.
9. Almeida JI, Kaufman J, Goeckeritz O, Chopra P, Evans MT, Hoheim $\mathrm{DF}$, et al. Radiofrequency Endovenous ClosureFAST versus Laser Ablation for the Treatment of Great Saphenous Reflux: A Multicenter, Single-blinded, Randomized Study (RECOVERY Study). J Vasc Interv Radiol 2009;20:752-9.

10. van der Geld CW, van den Bos RR, van Ruijven PW, Nijsten T, Neumann HA, van Gemert MJ. The heat-pipe resembling action of boiling bubbles in endovenous laser ablation. Lasers Med Sci 2010;25:907-9.

11. Malskat WS, Stokbroekx MA, van der Geld CW, Nijsten TE, van den Bos RR. Temperature profiles of 980- and 1,470-nm endovenous laser ablation, endovenous radiofrequency ablation Guess JJ. Endovenous chemical (and physical) treatments for varices: what's new? Phlebology 2014;19:45-8.

12. Malskat WS, Poluektova AA, van der Geld CW, Neumann HA, Weiss RA, Bruijninckx CM, et al. Endovenous laser ablation (EVLA): a review of mechanisms, modeling outcomes, and issues for debate. Lasers Med Sci 2014;29:393-403.

13. Wollin TA, Denstedt JD. The holmium laser in urology. J Clin Laser Med Surg 1998;16:13-20.

14. Janis LR, Kravitz RD, Wagner SS. The pulsed holmium: yttrium-aluminum-garnet laser. Applications to ankle arthroscopy. J Clin Laser Med Surg 1998;16:13-20.

15. Kou L, Labrie D, Chylek P. Refractive indices of water and ice in the 0.65- to 2.5- $\mu \mathrm{m}$ spectral range. Appl Opt 1993;32:3531-40.

16. Vuylsteke M, Van Dorpe J, Roelens J, De Bo T, Mordon S. Endovenous laser treatment: a morphological study in an animal model. Phlebology 2009;24:166-75.

17. Schmedt CG, Sroka R, Steckmeier S, Meissner OA, Babaryka G, Hunger $\mathrm{K}$, et al. Investigation on radiofrequency and laser $(980 \mathrm{~nm})$ effects after endoluminal treatment of saphneous vein insufficiency in an ex-vivo model. Eur J Vasc Endovasc Surg 2006;32:318-25.

18. Proebstle TM, Sandhofer M, Kargl A, Guel D, Rother W, Knop J, et $a l$. Thermal damage of the inner vein wall during endovenous laser treatment: key role of energy absorption by intravascular blood. Dermatol Surg 2002;28:596-600.

19. Corcos L, Dini S, De Anna D, Marangoni O, Ferlaino E, Procacci T, et al. The immediate effects of endovenous diode $808-\mathrm{nm}$ laser in the greater saphenous vein: morphologic study and clinical implications. J Vasc Surg 2005;41:1018-24.

20. Proebstle TM, Lehr HA, Kargl A, Espinola-Klein C, Rother W, Bethge $\mathrm{S}$, et al. Endovenous treatment of the greater saphenous vein with a 940-nm diode laser: thrombotic occlusion after endoluminal thermal damage by laser-generated steam bubbles. J Vasc Surg 2002;35:729-36.

21. Bush RG, Shamma HN, Hammond K. Histological changes occurring after endoluminal ablation with two diode lasers (940 and 1319 $\mathrm{nm}$ ) from acute changes to 4 months. Lasers Surg Med 2008;40:6769 .

22. Kansaku R, Sakakibara N, Amano A, Endo H, Shimabukuro T, Suesishi M. Histological difference between pulsed wave laser and continuous wave laser in endovenous laser ablation. Phlebology 2015;30:429-34

23. Samouillan V, Dandurand J, Lacabanne C, Stella A, Gargiulo M, Degani A, et al. Analysis of the molecular mobility of collagen and elastin in safe, atheromatous and aneurysmal aortas. Pathol Biol 2012;60:58-65.

24. Zhang Q, Huang SM, Meng LY, Wang XD, Ding JQ. Endovenous holmium laser treatment for varicose veins. Zhonghua Wai Ke Za Zhi 2004:4:1244-6.

25. Blaise s, Bosson JL, Diamand JM. Ultrasound-guided sclerotherapy of the great saphenous vein with $1 \%$ vs $3 \%$ Polidocanol Foam: a multicentre double-blind randomised trial with 3-year follow up. Eur J Vasc Endovasc Surg 2010;39:779-86.

26. Ceulen RPM, Bullens-Goessens YIJM, Pi-Van De Venne SJA. Outcomes and side effects of duplex-guided sclerotherpay in the treatment of great saphenouos veins with $1 \%$ vs $3 \%$ Polidocanol Foam: results of a randomized controlled trial with 1-year follow up. Dermatol Surg 2007;33:276-81. 


\section{COPYRIGHT $^{\circledR} 2017$ EDIZIONI MINERVA MEDICA}

GIANESINI

HOLMIUM LASER IN CVD TREATMENT

27. Thomasset SC, Butt Z, Liptrot S, Fairbrother BJ, Makhdoomi KR. Ultrasound Guided Foam Sclerotherapy: Factors Associated with Outcomes and Complications. Eur J Vasc Endovasc Surg 2010;40, $389 \mathrm{e} 392$.

28. Breu FX, Guggenbichler, Wollmann JC. 2nd European Conensus Meeting on Foam Sclerotherapy, 28-30 April 2006, Tegernsee, Germany. Vasa 2008;37(Suppl 71):1.

29. Shahid KR, Dellon AL, Amrami KK, Spinner RJ. Sciatic and peroneal nerve injuries after endovascular ablation of lower extremity varicosities: case reports and review of the literature. Ann Plast Surg 2015;74:64-8.

30. Bellmunt-Montoya S, Escribano JM, Dilme J, Martinez-Zapata MJ. CHIVA method for the treatment of chronic venous insufficiency. Cochrane Database Syst Rev 2015;6:CD009648.

31. Chan CY, Chen TC, Hsieh YK, Huang JH. Retrospective comparison of clinical outcomes between endovenous laser and saphenous vein-sparing surgery for treatment of varicose veins. World J Surg 2011;35:1679-86.
32. Nessbitt C, Eifell RK, Coyne P, Badri H, Bhattacharya V, Stansby G. Endovenous ablation (radiofrequency and laser) and foam sclerotherapy versus conventional surgery for great saphenous vein varices. Cochrane Database Syst Rev 2011;(10):CD005624.

33. Ferracani E. Internal laser valvuloplasty and venous remodelling using 1470 laser. Initial experience. Flebologia 2013;39-40.

34. Gianesini S, Menegatti E, Zuolo M, Tessari M, Ascanelli S, Occhionorelli $\mathrm{S}$, et al. Short endovenous laser ablation of the great saphenous vein in a modified CHIVA strategy. Veins and Lymphatics 2013;2;e21.

35. Gianesini S, Menegatti E, Zuolo M, Tessari M, Spath P, Ascanelli S, et al. Laser-assisted strategy for reflux abolition in a modified CHIVA approach. Veins and Lymphatics 2015;4.

36. Poluektova AA, Malskat WS, van Gemert MJ, Vuylsteke ME, Bruijninckx CM, Neumann HA, et al. Some controversies in endovenous laser ablation of varicose veins addressed by optical-thermal mathematical modeling. Lasers Med Sci 2014;29:441-52.

Conflicts of interest.-The authors certify that there is no conflict of interest with any financial organization regarding the material discussed in the manuscript. Congresses.- The content of this paper was accepted as a poster presentation at the Annual Meeting American Venous Forum, which was held in Orlando, FL, on February $24^{\text {th }}-26^{\text {th }}, 2016$.

Article first published online: February 12, 2016. - Manuscript accepted: February 8, 2016. - Manuscript received: December 10, 2015. 